\title{
Analysis of Innate and Adaptive Immunological Characteristics in Patients with IgG4-Related Disease
}

\author{
Kyoung-Hee Sohn ${ }^{a, b}$ Jongho Ham ${ }^{c, d}$ Soo Jie Chung ${ }^{a, b}$ Hye-Ryun Kang ${ }^{a, b}$ \\ Hye Young Kim ${ }^{b, c, d}$
}

aDepartment of Internal Medicine, Seoul National University College of Medicine, Seoul, Republic of Korea; b Institute of Allergy and Clinical Immunology, Seoul National University Medical Research Center, Seoul National University College of Medicine, Seoul, Republic of Korea; 'Department of Biomedical Sciences, Seoul National University College of Medicine, Seoul, Republic of Korea; 'Laboratory of Mucosal Immunology in Department of Biomedical Sciences, Seoul National University College of Medicine, Seoul, Republic of Korea

\section{Keywords}

IgG4-related disease $\cdot$ Monocyte $\cdot$ TGF- $\beta$. Plasma cells

\begin{abstract}
Background: Immunoglobulin G4-related disease (lgG4-RD) is a systemic immunological disorder characterized by fibroinflammatory conditions; however, the pathobiology of IgG4-RD has not been fully identified. Objective: This study aimed to analyze systemic differences of innate and adaptive immune cells from healthy controls and patients with IgG4-RD. Methods: Healthy controls $(n=9)$ and IgG4-RD patients ( $n=7$ ) were recruited with informed consent. Peripheral blood was collected from healthy controls and IgG4-RD patients, and three blood samples from IgG4-RD patients were re-collected two months after the last rituximab (RTX) treatment. The various immune cells and cytokine productions were measured by flow cytometry. Results: Blood $\mathrm{CD}_{14}{ }^{+}$monocytes and steady-state follicular helper $\mathrm{T}$ cells were increased in patients with IgG4-RD. However, there
\end{abstract}

K.-H.S. and J.H. contributed equally to this work. Edited by: O. Palomares, Madrid.

karger@karger.com www.karger.com/iaa Karger" (c) 2020 The Author(s)

Published by S. Karger AG, Basel

Karger

Open access

This article is licensed under the Creative Commons AttributionNonCommercial-NoDerivatives 4.0 International License (CC BYNC-ND) (http://www.karger.com/Services/OpenAccessLicense) Usage and distribution for commercial purposes as well as any distribution of modified material requires written permission. were no changes in other immune cell populations, including B cells, CD4 T cells, CD8 T cells, and innate lymphoid cells. Also, the TGF- $\beta$-producing $C D 14^{+}$monocytes were significantly augmented in patients with IgG4-RD. Two months after RTX treatment, total B cells $\left(C D 19^{+}\right)$were depleted; however, the expressions of TGF- $\beta$ from $\mathrm{CD}_{14}{ }^{+}$monocytes remained unchanged. Conclusion: These findings showed that IgG4-RD is related to the increment of $\mathrm{CD}_{14}{ }^{+}$monocytes. Besides, controlling increased TGF- $\beta$-producing CD14 ${ }^{+}$ monocytes with RTX treatment might be a conducive way to regulate IgG4-RD.

(c) 2020 The Author(s)

Published by S. Karger AG, Basel

\section{Introduction}

Immunoglobulin G4-related disease (IgG4-RD) is a systemic immunological disorder characterized by fibroinflammatory conditions that can involve almost any organ [1]. In the early stage of its discovery, IgG4-RD was 
considered as a subtype of Sjögren's syndrome [2]; however, apoptosis of acinar and ductal cells was not observed and serum IgG4 levels were high in IgG4-RD patients. Therefore, IgG4-RD was classified as a disease distinguishing Sjögren's syndrome clinically and histopathologically [3]. Although the pathobiology of IgG4-RD has not been fully characterized, previous studies confirmed that $\mathrm{CD} 4^{+}$cytotoxic $\mathrm{T}$ cells are clonally expanded into diseased tissues, and tissue fibrosis occurs due to excess production of type 2 cytokine (IL-4, IL-5, and IL-13) and regulatory cytokines (IL-10 and TGF- $\beta$ ) $[4,5]$. Along with these changes, follicular helper $\mathrm{T}$ ( $\mathrm{Tfh}$ ) cells, regulatory T cells (Treg), and plasma cells are increased in IgG4$\mathrm{RD}$, and their cross-talk induces IgG4 productions from plasma cells $[6,7]$.

Glucocorticoids are regarded as highly effective agents for the exertion of disease control in IgG4-RD. However, the discovery of expanded plasmablasts in patients with IgG4-RD and their correlation with disease activity leads to the use of rituximab (RTX, anti-CD20 antibody) on IgG4-RD [8]. Although the effects of RTX are generally observed rapidly, with symptomatic improvement, there has been little knowledge about the populations of circulating immune cells in patients with IgG4-RD and the effect of RTX on these populations. In this study, we aimed to (i) measure the changes in the innate and adaptive immune responses in IgG4-RD patient compared to healthy controls and (ii) compared the changes in the innate and adaptive immune cells before and after the RTX treatment.

\section{Materials and Methods}

\section{Cases}

IgG4-RD was defined according to the consensus statements from a multinational, multidisciplinary group of experts on IgG4$\mathrm{RD}$ [9]. Blood samples from seven IgG4-RD patients were collected at the time of diagnosis and re-collected from three patients who

Fig. 1. Plasma cells and TGF- $\beta$-producing CD14 ${ }^{+}$monocytes were increased in patients with IgG4-RD. a Gating strategies and frequencies of B-cell subsets from healthy control $(n=3)$ and patients with IgG4-RD $(n=6)$. Plasma cells $\left(\mathrm{CD} 19^{+} \mathrm{CD} 20^{-} \mathrm{CD} 38^{+}\right)$, germinal center (GC) B cells $\left(\mathrm{CD} 19^{+} \mathrm{CD} 20^{+} \mathrm{CD} 38^{+}\right)$, and memory B cells $\left(\mathrm{CD} 19^{+} \mathrm{CD} 27^{+} \mathrm{CD} 38^{-}\right)$. $\mathbf{b}$ Gating strategies and frequencies of Tfh cell subsets from healthy control and patients with IgG4-RD. Among CD4 ${ }^{+} \mathrm{T}$ cells, $\mathrm{CD} 45 \mathrm{RO}^{+} \mathrm{CXCR} 5^{+}$cells were further analyzed as CXCR3-PD- $1^{+}$steady-state $\mathrm{Tfh}$ and $\mathrm{CXCR} 3^{+} \mathrm{PD}-1^{+}$acute Tfh cells. c Gating strategy of monocytes $\left(\mathrm{CD} 14^{+}\right)$from healthy control and patients with IgG4-RD. d Dot plots of IL-10 and TGF- were in the asymptomatic state two months after RTX treatment. Nine blood samples were collected from sex- and age-matched healthy controls. Institutional review board approval was obtained for this study (IRB No. 1908-117-1056) at Seoul National University Hospital.

\section{Flow Cytometry Analysis}

Peripheral blood mononuclear cells were isolated and stained by mononuclear antibodies to analyze the changes of immune cells. To analyze cytokine productions, peripheral blood mononuclear cells were stimulated by phorbol 12-myristate 13-acetate and ionomycin or LPS in vitro. Stained immune cells were analyzed by BD LSRFortessa ${ }^{\mathrm{TM}} \mathrm{LSRII}$ and BD LSRFortessa ${ }^{\mathrm{TM}} \mathrm{X}-20$. Detailed materials and methods are available in online suppl. Materials and Methods; for all online suppl. material, see www. karger.com/doi/10.1159/000508699.

\section{Statistical Analysis}

All statistical analysis was performed using GraphPad Prism7 (GraphPad Software, CA, San Jose, USA). The determination of normality of data was based on Shapiro-Wilk test. Two unpaired groups were compared using 2-tailed Student's $t$ test for parametric measure or Mann-Whitney test for nonparametric measures. Wilcoxon matched-pairs signed rank test were used to compare of 2 paired groups. Values of measurements represent as mean \pm SD. $p$ value $<0.05$ was considered statistically significant.

\section{Results}

To investigate immunological changes in patients with IgG4-RD, blood samples were collected from 16 subjects (Nine healthy controls and seven IgG4-RD patients) (online suppl. Table 1). Initially, seven blood samples were drawn from the IgG4-RD patients at the time of diagnosis. Among seven IgG4-RD patients, three blood samples were re-collected two months after the administration of two doses of RTX (1,000 mg each) combined with methylprednisolone (40 mg).

The percentage of circulating B cell subsets, including plasma cells, germinal center (GC) B cells, and memory B cells, showed similar frequencies between IgG4-RD pa-

$\beta$-producing cells divided by CD14 expressions. e Percentages of IL- 10 and TGF- $\beta$-producing immune cells were calculated. IL-10 and TGF- $\beta$ productions were analyzed after in vitro stimulation with PMA/ionomycin $\left(\mathrm{CD} 4^{+} \mathrm{T}\right.$ cells, $\mathrm{CD} 8^{+} \mathrm{T}$ cells, $\mathrm{CD} 19^{+} \mathrm{B}$ cells, and ILCs) or LPS (CD14 $4^{+}$monocytes). Values represent the mean \pm SD. Mann-Whitney test was used to compare healthy control and IgG4-RD (a-c, e). ${ }^{*} p<0.05,{ }^{* *} p<0.01$. ns, not significant; IgG4-RD, immunoglobulin G4-related disease; PMA, phorbol 12-myristate 13-acetate; Tfh, follicular helper T; ILCs, innate lymphoid cells.

(For figure see next page.) 
tients and healthy controls (Fig. 1a). However, steady-state Tfh cells were significantly increased in patients with IgG4RD. Although IgG4-RD patients and healthy controls showed no difference in the population of CD4 and CD8 T cells (online suppl. Figs. 1a, $2 \mathrm{a}$ ), their IFN $\gamma$ productions were increased in IgG4-RD patients (online suppl. Figs. $1 \mathrm{~b}$, c, $2 \mathrm{~b}, \mathrm{c})$. Besides adaptive immune cells, innate immune cells, including innate lymphoid cells and monocytes, were

a
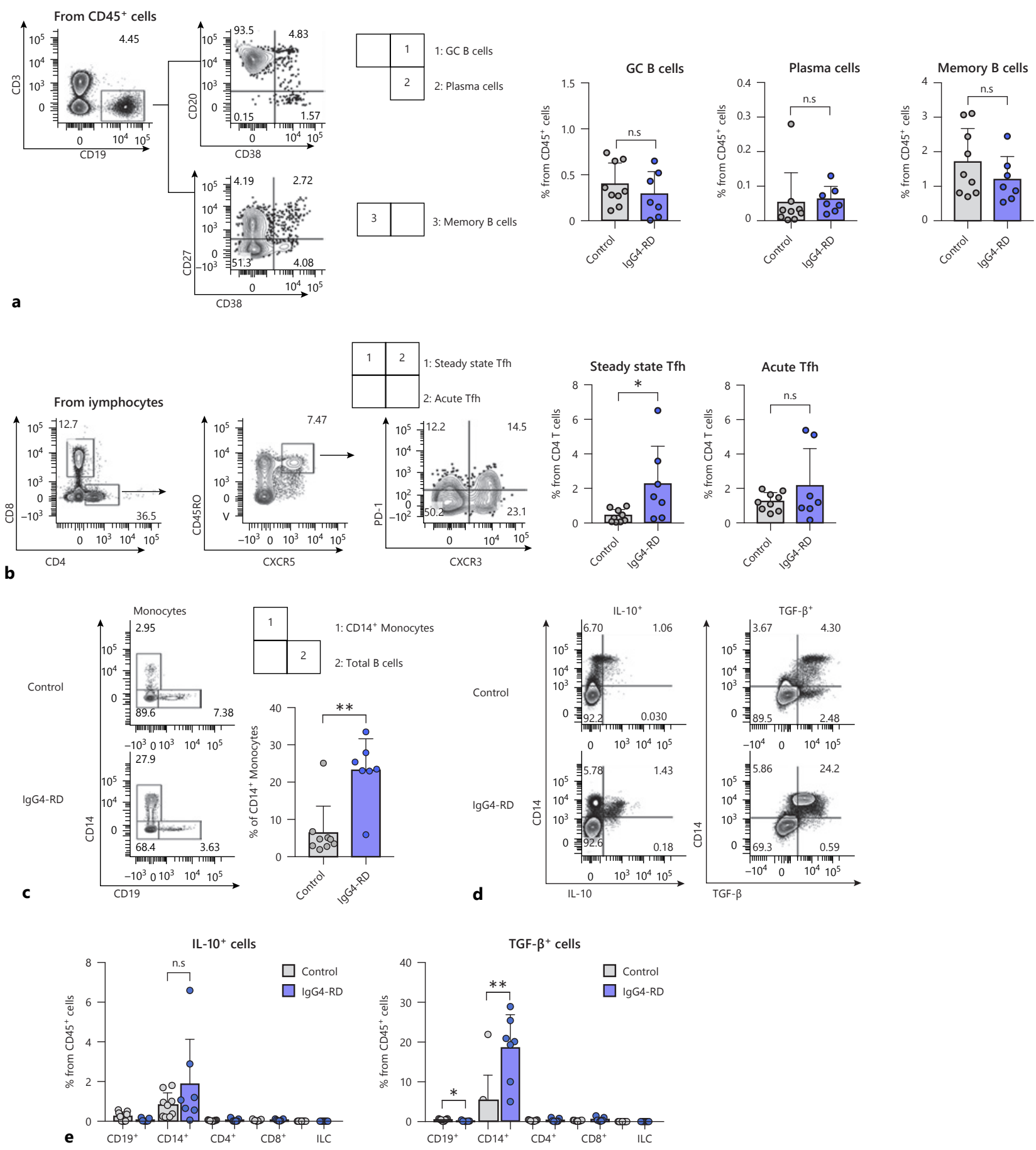

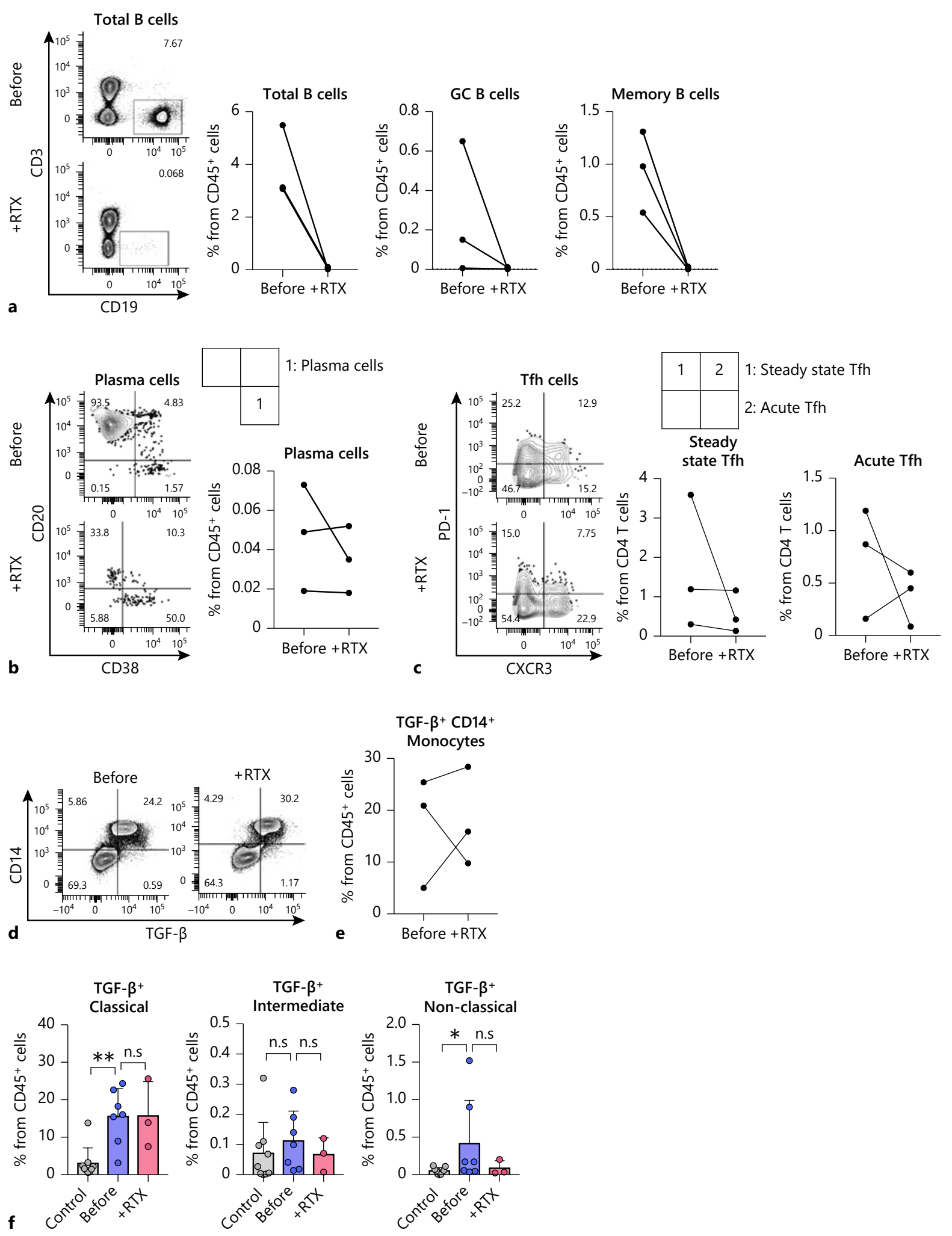

2

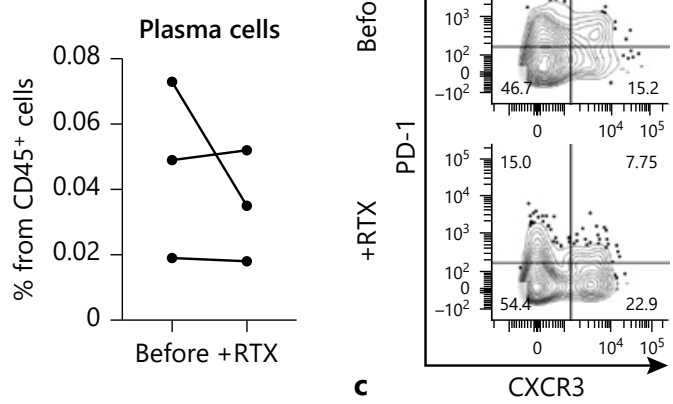

(For legend see next page.) 
also analyzed. The frequency of innate lymphoid cells (online suppl. Fig. 3a) and most of their cytokine productions (online suppl. Fig. 3b, c) were comparable to healthy control and patients with IgG4-RD. Instead, CD14 ${ }^{+}$monocytes were significantly increased in IgG4-RD patients (Fig. 1c).

Since storiform fibrosis is one of the major features of IgG4-RD, changes in IL- 10 and TGF- $\beta$ productions, known as cytokines for fibrosis induction, from circulating blood immune cells were analyzed. The levels of TGF- $\beta$ were augmented in IgG4-RD patients (Fig. 1d), and we noted $\mathrm{CD} 14^{+}$monocytes were the predominant source of TGF- $\beta$ (Fig. 1d, e). Although Treg and Tfh cells are known to produce IL-10 and TGF- $\beta$ in local tissue of IgG4-RD, our data showed that circulating $\mathrm{CD} 14^{+}$monocytes produce more IL-10 and TGF- $\beta$ than $\mathrm{CD} 4^{+} \mathrm{T}$ cells and $\mathrm{CD} 19^{+} \mathrm{B}$ cells (Fig. 1e). To determine which subsets of monocyte is associated with increased TGF- $\beta$ productions from different monocyte in the IgG4-RD patients and healthy controls, monocytes were subclassified by CD14 and CD16 expressions (online suppl.Fig. 4a). Classical monocytes $\left(\mathrm{CD} 14^{++} \mathrm{CD} 16^{-}\right)$ constituted the major population (26-67\%) of circulating monocytes (online suppl. Fig. 4b) and were predominantly increased in the IgG4-RD patients compared to controls (online suppl. Fig. 4b). However, there was no significant increase in the proportion of intermediate $\left(\mathrm{CD} 14^{++} \mathrm{CD} 16^{+}\right)$and nonclassical $\left(\mathrm{CD} 14^{+} \mathrm{CD} 16^{+}\right)$monocytes compared to healthy controls (online suppl. Fig. 4b).

Next, the changes in immune cells by RTX treatment was validated in IgG4-RD patients. First, the plasma cells, Tfh cells, and monocyte populations were compared before and after RTX treatment. RTX treatment effectively eliminated the total B cells, GC B cells, and memory B cell subsets (Fig. 2a), but the number of plasma cells, which secrete large quantities of antibody, remained after RTX treatment (Fig. 2b). Moreover, Tfh cells (Fig. 2c) and CD $14^{+}$monocytes (Fig. 2d) were not significantly changed

Fig. 2. RTX treatment did not alter plasma cells and TGF- $\beta$ secreting $\mathrm{CD}_{14}{ }^{+}$monocytes from the PBMCs of IgG4-RD patients. a Frequencies of total B cells $\left(\mathrm{CD} 19^{+}\right)$, GC B cells $\left(\mathrm{CD} 19^{+} \mathrm{CD} 20^{+} \mathrm{CD} 38^{+}\right)$, and memory B cells $\left(\mathrm{CD} 19^{+} \mathrm{CD} 27^{+} \mathrm{CD} 38^{-}\right)$ from PBMCs were compared before and after RTX treatment. $\mathbf{b}$, c The representative dot plot and percentage of plasma cells (b) and Thf (c) before and after RTX treatment. d, e Representative dot plot (d) and percentage of TGF- $\beta$-producing monocytes (e) before and after RTX treatment. f TGF- $\beta$-producing monocytes were further divided by CD14 and CD16 expression. Classical by RTX treatment. Second, we determined TGF- $\beta$ production from $\mathrm{CD} 14^{+}$monocytes and found that the level of TGF- $\beta$ was not affected by RTX treatment (Fig. $2 \mathrm{~d}$, e). Among $\mathrm{CD} 14^{+}$monocytes, classical monocytes secreted TGF- $\beta$ dominantly, and they were not affected by RTX treatment (Fig. 2f). Those data showed that RTX therapy effectively eliminated pan-B cells; however, there were remaining Tfh cells and TGF- $\beta$ in the blood from IgG4-RD, suggesting that these cells might be risk factors for sustaining inflammation.

\section{Discussion}

Here, we analyzed the innate and adaptive immunological changes in IgG4-RD patients. We found a significant increase in the number of Tfh cells and CD14 ${ }^{+}$ monocytes in patients with IgG4-RD. Moreover, the frequencies of plasma cells, Tfh cells, and $\mathrm{CD} 14^{+}$monocytes were not changed even after RTX treatment. RTX treatment was expected to cause direct depletion of circulating and tissue-resident $\mathrm{B}$ cells, thereby eliminating the progenitor to the plasma cells; however, we found that antibody-secreting cells, plasma cells, remained intact. Also, Tfh cells, that associated with B cell survivals and plasma cell generations, remained unchanged. Although B cell depletion appears to be an effective treatment strategy for IgG4-RD, the assessment of disease activity following treatment and appropriate timing of re-treatment remains challenging.

TGF- $\beta$ is a well-known cytokine that regulates immune responses and induces fibrosis by activating fibroblasts. In IgG4-RD pathophysiology, systemic fibrotic inflammation is a critical characteristic of IgG4-RD. Several studies had shown that increased IL-10 and TGF- $\beta$ secretion from Treg and Tfh cells in the inflamed lesions [4]. However, we found that circulating $\mathrm{CD} 14^{+}$monocyte produce TGF- $\beta$ much more than any other immune cells.
Increased Pathological Monocytes in IgG4-Related Disease Patients
$\left(\mathrm{CD} 14^{++} \mathrm{CD} 16^{-}\right)$, intermediate $\left(\mathrm{CD} 14^{++} \mathrm{CD} 16^{+}\right)$, and nonclassical monocytes $\left(\mathrm{CD} 14^{+} \mathrm{CD} 16^{+}\right)$were analyzed. Values represent the mean \pm SD. Wilcoxon matched-pairs signed rank test was used to compare before and after RTX-treated patients (a-c, e). MannWhitney test was used to compare control and IgG4-RD or before and after RTX-treated groups (f). ${ }^{*} p<0.05,{ }^{* *} p<0.01$. ns, not significant; IgG4-RD, immunoglobulin G4-related disease; RTX, rituximab; Tfh, follicular helper T; PBMCs, peripheral blood mononuclear cells. 
Besides, RTX treatment did not alter TGF- $\beta$ production from $\mathrm{CD} 14^{+}$monocytes. Since the fibrotic features are unlikely to respond to the currently available therapies, specially designed therapies are urgently needed to address fibrosis problems.

IgG4-RD is an inflammatory and fibrotic state involving innate and adaptive immune cells. Unfortunately, a large proportion of patients with IgG4-RD have relative contraindications to long-term glucocorticoid treatment, even at moderate to low doses. A better understanding of the pathophysiology of IgG4-RD may lead to a variety of exciting mechanism-based therapies, including the possibility of modulating TGF- $\beta$-producing monocytes and Tfh cells.

\section{Statement of Ethics}

Written informed consent was obtained from the subjects. Institutional review board approval was obtained for this study (IRB No. 1908-117-1056) at Seoul National University Hospital.

\section{Disclosure Statement}

The authors have no conflicts of interest to declare.

\section{Funding Sources}

This work was supported by Research Resettlement Fund for the new faculty of Seoul National University. This work was supported by the Korea Healthcare Technology R\&D Project, Ministry of Health and Welfare, Korea (HI15C1736), and the National Research Foundation of Korea (SRC 2017R1A5A1014560).

\section{Author Contributions}

Hye Young Kim and Hye-Ryun Kang conducted and supervised the manuscript development, Jongho Ham analyzed immune cell populations and statistical processing of the results, Kyoung-Hee Sohn and Soo Jie Chung recruited subjects and collected peripheral blood samples, and Hye Young Kim and Hye-Ryun Kang designed the conceptual framework of the present research.

\section{References}

1 Stone J, Zen Y, Deshpande V. IgG4-related disease. N Engl J Med. 2012;366(6):539-51.

2 Yamamoto M, Harada S, Ohara M, Suzuki C, Naishiro Y, Yamamoto H, et al. Clinical and pathological differences between Mikulicz's disease and Sjögren's syndrome. Rheumatology. 2005;44(2):227-34.

3 Yamamoto M, Takahashi H, Ohara M, Suzuki C, Naishiro Y, Yamamoto H, et al. A new conceptualization for Mikulicz's disease as an IgG4-related plasmacytic disease. Mod Rheumatol. 2006;16(6):335-40.

4 Miyoshi H, Uchida K, Taniguchi T, Yazumi S, Matsushita M, Takaoka M, et al. Circulating naïve and CD $4+\mathrm{CD} 25$ high regulatory $\mathrm{T}$ cells in patients with autoimmune pancreatitis. Pancreas. 2008;36(2):133-40.
5 Suzuki K, Tamaru J, Okuyama A, Kameda $\mathrm{H}$, Amano K, Nagasawa H, et al. IgG4-positive multi-organ lymphoproliferative syndrome manifesting as chronic symmetrical sclerosing dacryo-sialadenitis with subsequent secondary portal hypertension and remarkable IgG4-linked IL-4 elevation. Rheumatology. 2010;49(9):1789-91

6 Umehara H, Nakajima A, Nakamura T, Kawanami T, Tanaka M, Dong L, et al. IgG4related disease and its pathogenesis-cross-talk between innate and acquired immunity. Int Immunol. 2014;26(11):585-95.
7 Akiyama M, Suzuki K, Yasuoka H, Kaneko Y, Yamaoka K, Takeuchi T. Follicular helper T cells in the pathogenesis of IgG4-related disease. Rheumatology. 2018;57(2):236-45.

8 Mattoo H, Mahajan VS, Della-Torre E, Sekigami Y, Carruthers M, Wallace ZS, et al. De novo oligoclonal expansions of circulating plasmablasts in active and relapsing IgG4-related disease. J Allergy Clin Immunol. 2014; 134(3):679-87.

9 Umehara H, Okazaki K, Masaki Y, Kawano M, Yamamoto M, Saeki T, et al. Comprehensive diagnostic criteria for IgG4-related disease (IgG4-RD), 2011. Mod Rheumatol. 2012; 22(1):21-30. 